\title{
Article
}

\section{Polymeric arsenicals as scaffolds for functional and responsive hydrogels}

\author{
Tanaka, Joji, Song, Ji-Inn, Lunn, Andrew, Hand, Rachel, Hakkinen, \\ Satu, Schiller, Tara, Perrier, Sebastien, Davis, Tom and Wilson, Paul \\ Available at http://clok.uclan.ac.uk/28417/ \\ Tanaka, Joji, Song, Ji-Inn, Lunn, Andrew ORCID: 0000-0003-2884-2755, Hand, \\ Rachel, Hakkinen, Satu, Schiller, Tara, Perrier, Sebastien, Davis, Tom and \\ Wilson, Paul (2019) Polymeric arsenicals as scaffolds for functional and \\ responsive hydrogels. Journal of Materials Chemistry B, 7 . pp. 4263-4271. \\ ISSN 2050-750X
}

It is advisable to refer to the publisher's version if you intend to cite from the work. http://dx.doi.org/10.1039/C8TB02569]

For more information about UCLan's research in this area go to http://www.uclan.ac.uk/researchgroups/ and search for <name of research Group>.

For information about Research generally at UCLan please go to http://www.uclan.ac.uk/research/

All outputs in CLoK are protected by Intellectual Property Rights law, including Copyright law. Copyright, IPR and Moral Rights for the works on this site are retained by the individual authors and/or other copyright owners. Terms and conditions for use of this material are defined in the policies page.

\section{CLoK}

Central Lancashire online Knowledge www.clok.uclan.ac.uk

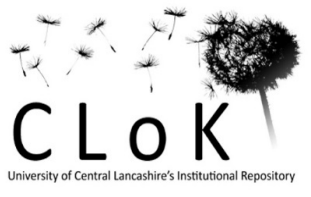




\section{Polymeric arsenicals as scaffolds for functional and responsive hydrogels}

Received 00th January 20xx, Accepted 00th January 20xx

DOI: $10.1039 / \times 0 \times x 00000 x$

www.rsc.org/

Joji Tanaka, ${ }^{a}$ Ji-Inn Song, ${ }^{a}$ Andrew M. Lunn, ${ }^{a}$ Rachel Hand, ${ }^{a}$ Satu Häkkinen, ${ }^{a}$ Tara L. Schiller, ${ }^{b}$ Sébastien Perrier, ${ }^{a, c, d}$ Thomas P. Davis, ${ }^{c}$ Paul Wilson. ${ }^{a, c *}$

Here arsenohydrogels are introduced for the first time as functional, tuneable and responsive hydrogels. The distinctive redox reactivity of arsenic has been exploited to crosslink high molecular weight $\left(M_{\mathrm{w}}>300 \mathrm{kDa}\right)$ polymeric arsenical scaffolds (PDMAm $\mathrm{x}$-co-AsAm $_{\mathrm{y}}$ ) via reductive coupling of $\mathrm{As}(\mathrm{V})$ to $\mathrm{As}(\mathrm{I})$ which proceeds with the formation of $A s-A s$ in the form of $A s(\mathrm{I})_{n}$ homocycles. Soft arsenohydrogels ( $\mathrm{G}^{\prime} \sim 400-1700 \mathrm{~Pa}$ ) that failed in compression tests at low compression and loading are formed when the polymer weight fraction is $2.5 \mathrm{wt} \%$. When the polymer weight fraction is increased to $10 \mathrm{wt} \%$ the mechanical properties (stiffness and relaxation) of the arsenohydrogels are significantly improved and correlate with the mole fraction of arsenic (AsAm, y) present in the copolymer scaffolds. Furthermore, increasing the mole fraction of AsAm, reduces the degree of swelling and increases the stability of the gels against hydrolysis and oxidation of the As-As crosslinks. The functionality of the polymeric arsenical scaffolds has also been exploited to load arsenohydrogels with a model organic arsenical drug. The rate and degree of release of the loaded organic arsenical under simulated oxidative stress $\left(\mathrm{H}_{2} \mathrm{O}_{2}\right)$ is inversely proportional to the mole fraction of arsenic in the original polymer scaffold. Finally, the polymeric arsenical scaffolds and the resulting arsenohydrogels have been shown to be non-toxic to NIH/3T3 (mouse fibroblast) and PC3 (human prostate cancer) cell lines. The properties and versitility of the arsenohydrogels alludes to their potential as a functional platform for biomaterials.

\section{Introduction}

Synthetic polymer hydrogels are materials composed of networks of hydrophilic polymers, cross-linked via covalent bonding or physical interactions such as hydrogen bonding, ${ }^{1}$ electrostatic interactions ${ }^{2}$ and host - guest ${ }^{3}$ / metal - ligand ${ }^{4}$ complexation..$^{5,6}$ They are defined by their durability and programmable physical and mechanical properties even at high water contents (>90\%), which lends itself to a number of emerging technologies, particularly in healthcare where they are being applied in areas such as wound dressings, ${ }^{7}$ diagnostics, ${ }^{8}$ drug delivery, ${ }^{9} 3 \mathrm{D}$ cell culture, ${ }^{10}$ tissue engineering ${ }^{11}$ and wearable technologies. ${ }^{12}$

Hydrogels formed through covalent bonding can exhibit static or dynamic properties based on the nature of the cross-linking involved. ${ }^{13}$ For example, the archetypal polyacrylamide hydrogel employed in gel electrophoresis, is an aqueous network of acrylamide irreversibly cross-linked by a bisacrylamide comonomer. ${ }^{14}$ Conversely, incorporation of functional groups capable of forming cleavable and/or dynamic covalent bonds into polymeric scaffolds has been employed to fabricate dynamic hydrogels which elicit spatial and temporal controlled bond formation and degradation, and in some cases self-healing properties. ${ }^{15,}{ }^{16}$ In this context Schiff bases (including hydrazone ${ }^{17}$ and oxime ${ }^{18}$ ), boronate

a Department of Chemistry, University of Warwick, Coventry, CV4 7AL, UK ${ }^{b}$ Warwick Manufacturing Group, University of Warwick, CV4 7AL, Coventry, UK 'ARC Centre of Excellence in Convergent Bio-Nano Science and Technology, Monash Institute of Pharmaceutical Sciences, Monash University (Parkville Campus), 399 Royal Parade, Parkville, Victoria 3152, Australia

'Warwick Medical School, University of Warwick, Gibbet Hill Road, Coventry, CV4 TAL, UK

Electronic Supplementary Information (ESI) available: [details of any supplementary information available should be included here]. See DOI: 10.1039/x0xx00000x esters $^{19}$ and disulfides ${ }^{20}$ are amongst those most widely explored in such systems. These dynamic bonds are sensitive to changes in the local $\mathrm{pH}$ or redox environment, or are competitively exchanged with biologically relevant nucleophiles to stimulate material response.

Organic arsenicals have diverse and distinct chemical reactivity which is dependent upon the oxidation state of the $\operatorname{As}(X)$ (e.g. $X=V, I I, I)$ centres present. However, concerns about the toxicity of arsenic have limited the use to organic arsenicals in polymer and materials science. A clinical renaissance in the use of arsenic trioxide to treat blood born malignancies and the subsequent development of more potent organic arsenical analogues, ${ }^{21}$ has inspired investigations into the potential of organic and polymeric arsenicals as a platform for functional and responsive (bio)materials. ${ }^{22}$ To this end, pentavalent arsenic, $\mathrm{As}(\mathrm{V})$, has been incorporated into well-defined polymer chains at the chain-end and/or the side-chains of polymers synthesised by radical deactivation radical polymerisation (RDRP), employing As-functional initiators and monomers respectively. These polymers have been shown to be non-toxic in vitro and have been exploited as reactive scaffolds for post-polymerisation modification ${ }^{23}$ and highly specific disulfide bond targeting linkers for protein/peptide-polymer conjugation ${ }^{24}$ via sequential reduction, to trivalent $\mathrm{As}(\mathrm{III})$, and reaction with thiol/disulfide containing molecules.

Most recently, thermoresponsive block copolymers containing organic arsenicals have been synthesised and assembled into polymeric arsenical nanoparticles. ${ }^{25,} 26$ One such approach adopts reductive conditions $\left(\mathrm{H}_{3} \mathrm{PO}_{2}, \mathrm{KI}\right)$ at elevated temperatures to generate nanoparticles stabilised as a result of reductive coupling from $\operatorname{As}(\mathrm{V})$ to $\mathrm{As}(\mathrm{I}){ }^{25}$ This has previously been reported to proceed with the formation As-As bonds in the form of $\mathrm{As}(\mathrm{I})_{n}$ homocyclic oligomers. ${ }^{27}$ The stability of the resulting nanoparticles in aqueous and model biological solutions ( $5 \mathrm{mM}$ glutathione) was dependent 
upon the mole ratio of $A s(V)$ in the initial monomer feed and all were responsive towards oxidation with hydrogen peroxide. To the best of our knowledge, this is the only example of cross-linking polymers using the redox chemistry of organic arsenicals. Herein, we demonstrate for the first time that reductive coupling of $A s(V)$ to $\mathrm{As}(\mathrm{I})$ in hydrophilic polymeric arsenicals can be used to furnish macroscopic arsenohydrogels. The resulting gels are non-toxic and their physical properties depend upon the As(V) mole fraction and the polymer loading in solution (wt\%).

\section{Experimental}

\section{Materials and instruments:}

AsAm was synthesised according to the literature. ${ }^{25} \mathrm{~N}, \mathrm{~N}$ Dimethylacrylamide (DMA) were filtered through a basic aluminium oxide (activated, basic, Brockman I, standard grade) to remove the radical inhibitor. 2,2'-azobis[2-(2-imidazolin-2yl)propane] dihydrochloride (VA-044, Wako), hypophosphoric acid and HPCLgrade $\mathrm{H}_{2} \mathrm{O}$ (sigma-aldrich, 50\%) were used without further purification. NIH/3T3 (ECACC catalogue no. 93061524) and PC3 (ECACC catalogue no. 90112714) cell-lines were obtained from the European collection of cell cultures (ECACC).

Nuclear Magnetic Resonance (NMR) spectroscopy $\left({ }^{1} \mathrm{H} \quad \mathrm{NMR}\right.$ spectra) were recorded on a Bruker HD 400 spectrometer (400 $\mathrm{MHz}$ ) at $27{ }^{\circ} \mathrm{C}$ using $\mathrm{D}_{2} \mathrm{O}$ as solvent and the residual proton signal of the solvent $(\delta \mathrm{H}=4.75 \mathrm{ppm})$ was used as internal reference. Chemical shift values $(\delta)$ are reported in ppm. ACDLABS software was used to analyse the data obtained. Number-average molar masses $\left(M_{n, S E C}\right)$ and dispersity values $(\Theta)$ were determined using Size exclusion Chromatography (SEC). Agilent PL50 instrument equipped with differential refractive index (DRI) detector. The system was equipped with Aquagel $\mathrm{OH}$ mixed $\mathrm{M}$ column $(300 \times 7.5 \mathrm{~mm})$ was used alongside with an $8 \mu \mathrm{m}$ aquagel guard column The mobile phase used was $80 \%$ $\mathrm{NaNO}_{3}$ in water at $0.1 \mathrm{M}$ and $20 \%$ methanol. Samples were run at $1 \mathrm{ml} / \mathrm{min}$ at $35^{\circ} \mathrm{C}$. Poly(ethylene oxide) standards (Agilent EasyVials) were used for calibration. Analyte samples were filtered through a membrane with $0.45 \mu \mathrm{m}$ pore size before injection. FT-IR spectrometer using a Golden Gate diamond attenuated total reflection cell and OPUS software was used to analyse the data.

\section{Rheology}

The transition from solution phase to gel phase was monitored by following the storage moduli and loss moduli. Measurements were performed on an Anton Paar MCR 302 rheometer using a parallel plate with diameter of $50 \mathrm{~mm}$ and measuring gap of $1 \mathrm{~mm}$. The normal force was kept constant at $0 \mathrm{~N}$ during measurements and all measurements were performed at $60{ }^{\circ} \mathrm{C}$. Experiments were performed using freshly prepared gel formulations ( $2 \mathrm{~mL}$, scale) . Gel formation was monitored with constant frequency of $10 \mathrm{rad} \mathrm{s}^{-1}$ and a constant strain of $1.0 \%$. When conducting the amplitude sweep, a constant frequency of $10 \mathrm{rad} \mathrm{s}^{-1}$ was applied and strain was ramped logarithmically from $1 \%$ to $500 \%$. For the frequency sweep, a constant strain of $1.0 \%$ was applied and frequency was ramped logarithmically from 0.1 to $100 \mathrm{rad} \mathrm{s}^{-1}$. All the data was analysed using RheoCompass software.

\section{Dynamic mechanical analysis (DMA)}

Dynamic mechanical analysis was performed on a Perkin Elmer DMA8000 in tension mode. Frequency sweeps were performed from 1 to $25 \mathrm{~Hz}$ at room temperature (approximately $25^{\circ} \mathrm{C}$ ). Hydrogels were prepared in silicone moulds as standard and then cut to size before mounting in the DMA (approximately $13 \mathrm{~mm}$ width, $4 \mathrm{~mm}$ thickness).

\section{Compression test}

An Instron universal tester 3367 (calibrated both with tensile and compression mode) fitted with a $500 \mathrm{~N}$ load cell and compression plates was used for compression testing of the arsenohydrogels. Hydrogels were prepared in moulds then cut to size before mounting (approximately $15 \mathrm{~mm}$ width, $5 \mathrm{~mm}$ thickness). To ensure moisture content was consistent, the samples were wrapped in cling film prior to testing, this was then opened on the compression plates for ease of collection of sample after testing (see Fig S11). The extension was zeroed prior to starting data collection when the top plate was starting to load the sample. All data was initially processed in Bluehill software and then plotted using graphical software. Each arsenohydrogel was compressed to a fixed load of $5 \mathrm{~N}$ and held for 30 secs to generate representative stress/strain curves, quantify gel stiffness (Young's Modulus, $Y$ ) and qualitatively investigate the relaxation properties. The $10 \mathrm{wt} \%$ samples were retested three times on the same sample to check elasticity.

\section{Reverse Phase High performance liquid chromatography (RP-HPLC)}

Both sample analysis conducted from a RP-HPLC system (Agilent 1260 infinity series stack) equipped with a 1260 Quat Pump VL, a degasser and a fraction collector (FC-AS). Samples were injected using Agilent 1260 auto-sampler with $5 \mu \mathrm{L}$ injection (Draw and injection of $200 \mu \mathrm{L} / \mathrm{min})$. The RP-HPLC was fitted with Eclipse XDBC18 column ( $150 \times 4.6 \mathrm{~mm}) 5$ micron packing (100Á). Detection was achieved using an Agilent 1260 variable wavelength detector connected in series with UV detection monitored at $280 \mathrm{~nm}$. The total flow rate was set to $1.0 \mathrm{~mL} / \mathrm{min}$ and the temperature of the column was set to $20^{\circ} \mathrm{C}$. The mobile phase condition is as follows. Mobile phase A: $100 \%$ water with $0.04 \% \mathrm{v} / \mathrm{v}$ TFA; Mobile phase $\mathrm{B}$ : $100 \% \mathrm{MeCN}$ with $0.04 \% \mathrm{v} / \mathrm{v}$ TFA (see SI for gradient).

\section{SEM and EDX analysis}

SEM analysis together with EDX was performed to determine the pore structure and arsenic content of the gels. Freshly prepared arsenohydrogels (P1 - P4, 10 wt\%) were initially dialysed against water to remove the reducing agents. Cross sections $\left(3 \mathrm{~mm}^{2}\right)$ for analysis were prepared by freezing the purified hydrogels with liquid $\mathrm{N}_{2}$ before slicing across the bulk of the hydrogel using a scalpel to expose the internal structure. Samples were mounted onto SEM 
stages using double sided conductive copper tape, which served as an adhesive and provided electrostatic screening. The samples were subsequently coated in gold for 15 seconds using a Polaron 5C 7640 sputter coater and the surface structure visualised using a Zeiss Gemini SEM- field emission scanning electron microscope at an accelerating voltage of either 10 or $15 \mathrm{keV}$. Elemental analysis was carried out during SEM imaging on the same samples using an Oxford instruments X-Max 150 large area SDD electron dispersive X-ray analysis (EDX) detector.

\section{Cell viability}

$\mathrm{NIH} / 3 \mathrm{~T} 3$ (mouse embryonic fibroblasts) cells were cultured in DMEM medium supplemented with $10 \%$ bovine calf serum, $2 \mathrm{mM}$ glutamine and $1 \%$ penicillin/streptomycin at $310 \mathrm{~K}$ in a $5 \% \mathrm{CO}_{2}$. PC3 (human prostate cancer) cells were cultured in DMEM medium supplemented with $10 \%$ foetal bovine serum, $2 \mathrm{mM}$ glutamine and $1 \%$ penicillin/streptomycin at $310 \mathrm{~K}$ in a $5 \% \mathrm{CO}_{2}$. For cell viability evaluation, $\mathrm{NIH} / 3 \mathrm{~T} 3$ and $\mathrm{PC} 3$ cells were seeded in a 96 well plate at a density of $1 \times 10^{4}$ cells per well. After 16 hours, the culture medium was replaced by fresh media containing a series of dilution of the polymers $\left(8,4,2,1,0.5,0.25 \mathrm{mgml}^{-1}\right)$, prepared from stock solutions in media at $8 \mathrm{mgml}^{-1}$ Following 24 hours incubation, the polymer containing medium was removed and each well was washed with fresh medium. The cells were incubated with a freshly prepared solution of XTT $\left(0.25 \mathrm{mg} / \mathrm{mL}^{-1}\right)$ and $\mathrm{N}$-methyl dibenzopyrazine methyl sulfate $(6.25 \mu \mathrm{M})$ in medium for 16 hours. Absorbance of the samples was finally measured using a plate reader at $450 \mathrm{~nm}$ and $650 \mathrm{~nm}$. The data presented are representative of a minimum of two independent experiments where each sample was measured in triplicate. Errors reported correspond to the standard deviation of the mean.

\section{Fluorescent confocal imaging of cells seeded in arsenohydrogels}

In each chamber slide, 30000 cells of NIH/3T3 (mouse embryonic fibroblasts) or PC3 (prostate cancer cell-line) in $300 \mu \mathrm{l}$ of DMEM media were seeded together with the dried hydrogels (vide infra). Also, the control cells without a hydrogel were prepared and incubated for 24 hours at $310 \mathrm{~K}$ in a $5 \% \mathrm{CO}_{2}$. The co-culture of $\mathrm{NIH} / 3 \mathrm{~T} 3$ or PC3 and hydrogel was stained by adding $12 \mathrm{ul}$ dye Hoechst $33342(0.1 \mathrm{mg} / \mathrm{ml})$ which targets nucleus (30 min, $310 \mathrm{~K}$ ). Samples were analysed using a Zeiss LSM710 confocal laser scanning microscope (Diode laser; excitation: $405 \mathrm{~nm}$; blue emission: 410-585 $\mathrm{nm})$. 12-bit images were obtained at room temperature using an EC Epiplan-Neofluar 20x /0.50HD M27 and a C-Apochromat 63X /1.20 W Korr M27 with ImmersolW immersion fluid on the objective lens on the microscope. The image stacks were projected along the z-axis using maximum-intensity projections. Data were processed using ZEN 2012 software for Windows (Zeiss).

\section{Synthetic methods}

General Procedure for polymer synthesis via Free Radical Polymerisation. AsAm was solubilised in water with 1 eq of Sodium Hydroxide and added into a cooled aqueous solution of DMA (1 M) with VA-044 (0.01 eq with respect to total monomer content). The solution was degassed for 15 minutes before heating the solution at $90{ }^{\circ} \mathrm{C}$ for 2 hours. The full consumption of the monomer was confirmed by NMR before freeze drying directly to yield white solids (>99\%).

General Procedure for arsenohydrogel synthesis. For 2.5 wt \% gels $25 \mathrm{mg}$ of AsAm bearing polymers (P1-P4) was initially dissolved in $800 \mu \mathrm{L}$ of HPLC grade water before adding $200 \mu \mathrm{L}$ of concentrated hypophosphoric acid solution (50\%) and $10 \mu \mathrm{L}$ of $3 \mathrm{wt} \%$ potassium iodide solution. The solution was heated at $60^{\circ} \mathrm{C}$ for 30 minutes, this resulted in successful clear gel formation however P3 and P4 macroscopic gel contraction was observed. For 10.0 wt \% gels 100 $\mathrm{mg}$ of AsAm bearing polymers (P1-P4) was initially dissolved in 800 $\mu \mathrm{L}$ of HPLC grade water before adding the $200 \mu \mathrm{L}$ of concentrated hypophosphoric acid solution (50\%) and $10 \mu \mathrm{L}$ of $3 \mathrm{wt} \%$ potassium iodide solution. The solution was heated at $60^{\circ} \mathrm{C}$ for 30 minutes, this resulted in formation of pale yellow gels, stable to syneresis.

Swelling test. Freshly prepared arsenohydrogels (10 wt\%) were dried to constant mass then immersed in PBS ( $\mathrm{pH}$ 7.4), glutathione (GSH, 5 $\mathrm{mM}$ ) and hydrogen peroxide $\left(\mathrm{H}_{2} \mathrm{O}_{2}, 5 \mathrm{mM}\right)$ to investigate swelling in model biological media and under simulated reductive and oxidative stress respectively. The arsenohydrogels were periodically removed from solution, excess water was removed using tissue and the swelling ratio was determined using $\left(W_{s}-W_{0} / W_{0}\right) \times 100$ (where $W_{s}$ is the mass of the swollen gel and $W_{0}$ is the mass of dried gel).

Gel Prep for Cell seeding. 10 wt\% arsenohydrogels were prepared as described above, in $2 \mathrm{ml}$ solution on a $3 \mathrm{~cm}$ diameter silicon mould. The gels were then dialysed in $100 \mathrm{ml}$ deionised water over 24 hours changing the water 6 to 8 times. Dried arsenohydrogels were obtained by lyophilisation. 

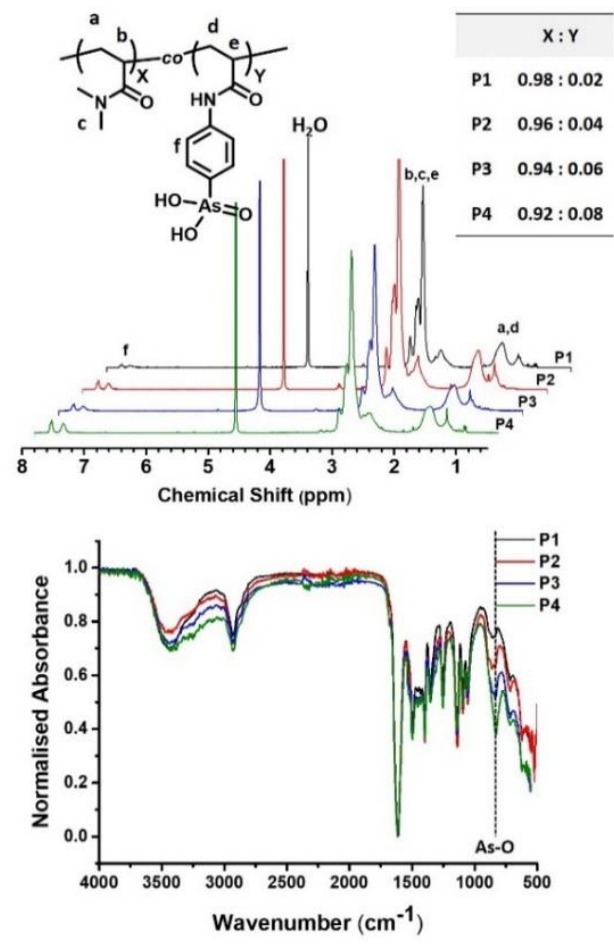

Fig. 1. NMR (top) and FT-IR (bottom) of polymeric arsenical scaffolds $\mathrm{PDAm}_{\mathrm{x}}-\mathrm{CO}-\mathrm{AsAm}_{\mathrm{y}}$ synthesised by free radical polymerisation.

Loading arsenohydrogels with model organic arsenical. For $2.5 \mathrm{wt}$ $\%$ gels $250 \mathrm{mg}$ of AsAm bearing polymers (P1-P4) was initially dissolved in $8 \mathrm{ml}$ of HPLC grade water before adding the $2 \mathrm{~mL}$ arsanilic acid (380 mg) freshly dissolved in concentrated hypophosphoric acid solution (50\%) and $100 \mu \mathrm{L}$ of $3 \mathrm{wt} \%$ potassium iodide solution. The solution was heated at $60{ }^{\circ} \mathrm{C}$ for $4 \mathrm{hrs}$, this resulted in dark red gels.

Release study of the arsanilic acid loaded arsenohydrogels with RPHPLC. The 2.5 wt\% gels described above were loaded with arsanilic acid in $50 \mathrm{ml}$ falcon tubes in HPLC grade water, filling up to $50 \mathrm{ml}$ line. The aqueous phase was stirred regularly without disturbing the gels, $200 \mu \mathrm{L}$ sample from aqueous phase was taken at $3 \mathrm{hr}, 12 \mathrm{hr}, 24 \mathrm{hr}$, $48 \mathrm{hr}$ and $144 \mathrm{hr}$ for HPLC analysis. The arsanilic acid released was identified by comparing the arsanilic acid (in hypophosphoric acid solution) to assign the retention time of the arsanilic acid released. The height of the intensity of the peak corresponding to arsanilic acid was measured and compared to the theoretical maximum concentration after release $\left(7.6 \mathrm{mgml}^{-1}\right)$.
Hydrogen peroxide mediated release study of the arsanilic acid loaded arsenohydrogels with RP-HPLC. The above procedure was repeated in parallel with addition of $200 \mu \mathrm{L}$ of $30 \mathrm{wt} \% \mathrm{H}_{2} \mathrm{O}_{2}$ (approximately stoichiometrically equivalent to arsanilic acid).

\section{Results and Discussion}

\section{Polymeric arsenical synthesis}

For the preparation of high molecular weight hydrophilic As(V)functional polymer scaffolds, the As(V)-functional acrylamide monomer (AsAm) reported in our previous work, ${ }^{25}$ was copolymerised with hydrophilic acrylamide monomer dimethylacrylamide (DMAm) using free radical polymerisation. Water soluble initiator (VA0-44) was employed at $90{ }^{\circ} \mathrm{C}$ targeting high monomer conversions and high molecular weight polymers. The reactions reached full conversion with respect to both monomers within $2 \mathrm{hrs}$ and the resulting polymers were directly lyophilised without further purification. The PDMAm ${ }_{\mathrm{x}}$-Co-AsAm $\mathrm{y}$ polymers (P1 P4, Table S1) were synthesised with increasing AsAm functionality as observed by NMR (Fig. 1, top). The percentage of AsAm was calculated by comparing either $-\mathrm{CH}_{2}$ the backbone of DMAm and AsAm (1.0 - $1.8 \mathrm{ppm})$ or $\mathrm{CH}_{3}$ - side chain of DMAm with $-\mathrm{CH}$ - of the backbone $(2.1-3.0 \mathrm{pm})$ with aromatic AsAm protons (7.2-7.8 ppm). Increasing Arsenic content was also confirmed by the increase in $u=$ $854 \mathrm{~cm}^{-1}$ corresponding to the As-O absorption in IR spectroscopy (Fig. 1, bottom). Molecular weight data was obtained by aqueous size exclusion chromatography (SEC) which revealed that each polymer had high molecular weight $\left(M_{\mathrm{w}}>300 \mathrm{kDa}\right.$, Fig. S1).

\section{Hydrogel preparation and characterisation}

The polymers were cross-linked via the reductive coupling method described in our previous work which was inspired by the synthesis and structural elucidation of Salvarsen (Fig. 2A). ${ }^{28}$ Hydrogels were formed at $2.5 \mathrm{wt} \%$ and $10 \mathrm{wt} \%$ polymer after heating at $60{ }^{\circ} \mathrm{C}$ in the presence of aqueous $\mathrm{H}_{3} \mathrm{PO}_{2}$ and $\mathrm{KI}$ for 30 minutes, according to qualitative inversion tests (Fig. 2B). 
A

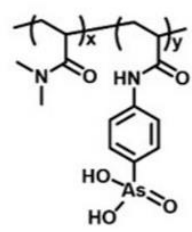

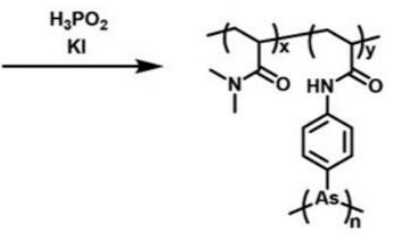

B

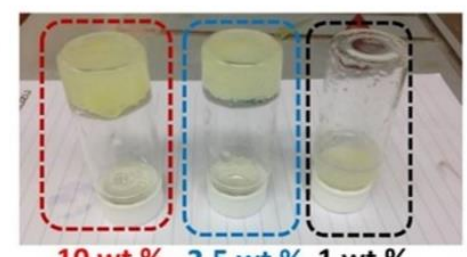

\section{C}

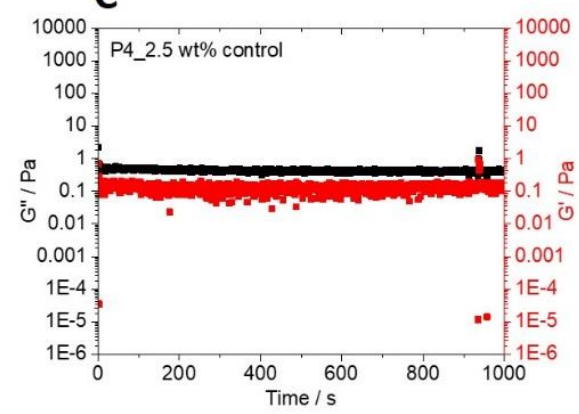

D

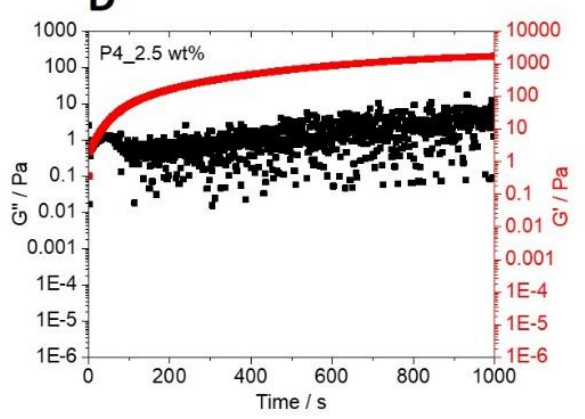

10 wt \% 2.5 wt \% 1 wt \%

Fig. 2. (A) General scheme for the formation of arsenohydrogels by reductive coupling of polymeric arsenical scaffolds; (B) Inverse test qualitatively demonstrating gelation at $2.5 \mathrm{wt} \%$ and $10 \mathrm{wt} \%$ with no gelation occurring at $1 \mathrm{wt} \%$; (C) Rheology of P4 (2.5 wt\%) in the absence of reducing agents performed in oscillation mode with strain $=1.0 \%$, frequency $=10 \mathrm{rad} . \mathrm{s}^{-1}$ and temperature $=60^{\circ} \mathrm{C} ;(\mathrm{D}) \mathrm{Rheology}$ of $\mathrm{P4}(2.5$ wt\%) in the presence of reducing agents $\left(\mathrm{H}_{3} \mathrm{PO}_{2}, \mathrm{KI}\right)$ performed in oscillation mode with strain $=1 \%$, frequency $=10$ rad. $\mathrm{s}^{-1}$ and temperature $=60^{\circ} \mathrm{C} ;(\mathrm{E})$ Plot of final storage modulus $\left(\mathrm{G}^{\prime}{ }_{\text {end }}\right)$ and gel time $\left(\mathrm{G}^{\prime}>\mathrm{G}^{\prime \prime}\right)$ for gels formulated using P1 $-\mathbf{P 4}$.

Attempts to form gels at $1 \mathrm{wt} \%$ of the arsenical polymers were unsuccessful as the gels collapsed to a heterogeneous precipitate. The gels exhibit a pale yellow colour which is consistent with the formation of cyclo-oligoarsines derived from phenylarsine derivatives. ${ }^{27}$ The intensity of the colouration qualitatively increases as a function of the cross-linking. Interestingly P3 and P4 with increased amounts of AsAm units underwent syneresis at $2.5 \mathrm{wt} \%$ within 2 hours of initial gel formation, expelling $40 \%$ of the aqueous solution (Fig. S2). This macroscopic contraction is typically observed with highly cross-linked polymeric gels at low polymer weight concentration. ${ }^{29}$
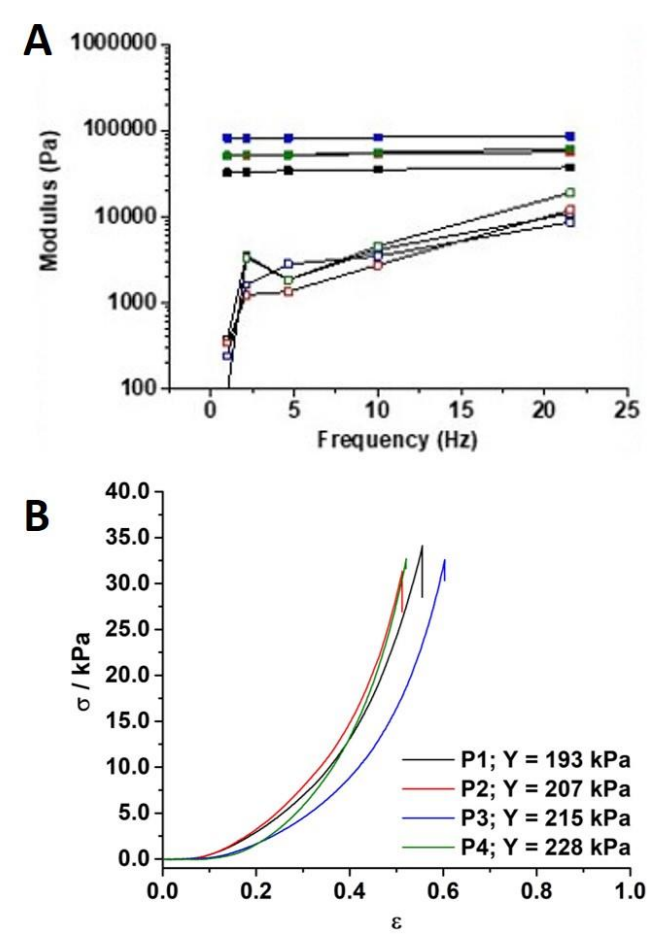

Fig 3. (A) Frequency sweep of arsenohydrogels from DMA analysis. Storage moduli (filled in squares) and loss moduli (empty squares) of P1 (black), P2 (red), P3 (blue) and P4 (green). (B) Stress/strain curve of the arsenohydrogels derived from P1 (black), P2 (red), P3 (blue) and P4 (green).

The formation of the 2.5 wt \% gels was followed by rheology in oscillation mode ( $1.0 \%$ strain) at $60{ }^{\circ} \mathrm{C}$. In the absence of reducing 
agents, gelation did not occur, even when $\mathbf{P 4}$ containing the largest mole fraction of the AsAm (8 mol\%) was used (Fig. 2C). When rheology was repeated in the presence of $\mathrm{H}_{3} \mathrm{PO}_{2}$ and $\mathrm{KI}$, transition from liquid to gel was observed at the cross over point between the storage $\left(G^{\prime}\right)$ and loss $\left(G^{\prime \prime}\right)$ moduli. The gel point was inversely proportional to the AsAm monomer feed (Fig. 2E, S3-S5). For example, P1 (2 mol\% AsAm) underwent gelation within 130 secs (Fig. S3), whilst P4 (8 mol\% AsAm) underwent gelation within 5 secs (Fig. 2D). Likewise, increasing the AsAm feed ratio increased the storage modulus obtained at the endpoint $\left(\mathrm{G}^{\prime}\right.$ end $)$ of the rheology experiments with $\mathbf{P} \mathbf{1}$ and $\mathbf{P} \mathbf{2}$ reaching $\mathrm{G}^{\prime}$ end values of 250 and $400 \mathrm{~Pa}$ respectively, whilst P3 and $\mathbf{P 4}$ had $\mathrm{G}^{\prime}$ end values of 1200 and $1700 \mathrm{~Pa}$ respectively (Fig. 2E). Rheology was also used to assess the selfhealing ability of the arsenohydrogels. Despite the potentially dynamic nature of the arsine bonds, ${ }^{30-33}$ the gels were not selfhealable as indicated by the loss of gel integrity observed in the $2^{\text {nd }}$ cycle of the amplitude sweep during rheology of P1 (2.5 wt\%, Fig. S6). Compression tests were performed on arsenohydrogels (2.5 wt\%) to generate stress/strain curves (Fig. S7-S10). Although the gels (P1 - P4) at $2.5 \mathrm{wt} \%$ failed at low stress/strain, the amount of stress/strain required to reach failure increased as a function of the AsAm mole fraction. For example, $\mathbf{P} \mathbf{1}$ failed at $0.6 \mathrm{kPa}$ stress and 0.42 strain (Fig. S7, S11), whilst P4 failed at 9 kPa stress and 0.5 strain (Fig. S10).

When arsenohydrogels were prepared at $10 \mathrm{wt} \%$ polymer the macroscopic structure was retained with no syneresis observed irrespective of the AsAm feed ratio. The viscoelastic properties of these hydrogels were determined by Dynamic Mechanical Analysis (DMA) in frequency sweep mode. The $\mathrm{G}^{\prime}(33-81 \mathrm{kPa})$ was consistently higher than $G^{\prime \prime}$ across the range of frequency tested, indicating the hydrogels were stable and behaved as viscoelastic solids (Fig. 3A). Increasing the polymer weight fraction to $10 \mathrm{wt} \%$ improved the mechanical properties of the arsenohydrogels. Each gel was compressed to a fixed load of $5 \mathrm{~N}$ and held for 30 secs to generate representative stress/strain curves, quantify gel stiffness (Young's Modulus, Y) and qualitatively investigate the relaxation properties (Fig. 3B). Increasing the AsAm mole fraction increased the stiffness of the gels formed with the Young's modulus increasing from $193 \mathrm{kPa}$ (P1) to $228 \mathrm{kPa}$ (P4). With respect to relaxation, the trend was reserved with arsenohydrogels derived from $\mathbf{P 1}$ and $\mathbf{P 2}$ exhibiting greater stress dissipation whilst maintaining the $5 \mathrm{~N}$ load for 30 secs after compression. The elastic properties of the arsenohydrogels was exemplified by cycling the gels derived from P3 and P4 3 times with little change in the mechanical properties (Fig. S12, S13).

The dry-state morphology of the purified arsenohydrogels (10 wt\%) was investigated by scanning electron microscopy (SEM) after dialysis and lyophilisation. The gels from P1 and P2 with 2 mol\% and 4 mol\% AsAm monomer feeds respectively showed no cross sectional microstructure (Fig. S14). The microstructure of these gels is compromised during the dialysis process due to partial hydrolysis of the As-As bonds (vide infra). Increasing the AsAm feed to $6 \mathrm{~mol} \%$
(P3) and $8 \mathrm{~mol} \%$ (P4) was expected to afford a higher degree of crosslinking and pleasingly this resulted in retention of porous, crosslinked gel microstructures (Fig. 4). This qualitatively indicates that the hydrolytic stability of the arsenohydrogels is proportional to the degree of cross-linking which increases as a function of the AsAm monomer feed. The increasing AsAm feed in the polymers is reflected in the arsenic content present in the final arsenohydrogels P1 (2.61 wt\%) - P4 (6.41 wt\%), which was quantified by EnergyDispersive X-ray (EDX) Spectroscopy (Table S2).

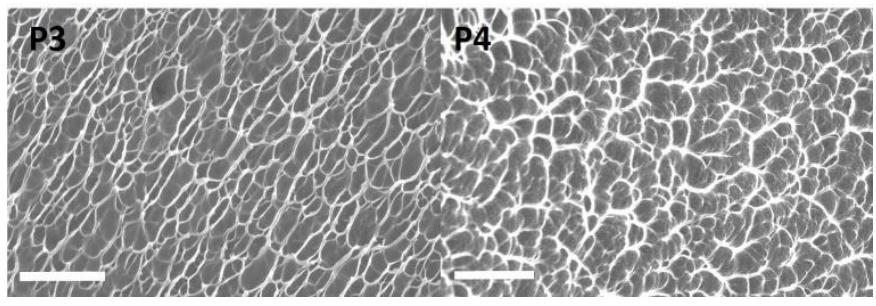

Fig 4. Scanning electron microscopy of dry 10 wt \% arsenohydrogels after dialysis and lyophilisation. P3 = $6 \mathrm{~mol} \%$ AsAm; P4 = $8 \mathrm{~mol} \%$ AsAm (Scale bar $=2 \mu \mathrm{m}$ ).

The stability and swelling characteristics of the arsenohydrogels (10 wt \%) was investigated in PBS buffer ( $\mathrm{pH} 7.4$ ), glutathione (GSH, 5 $\mathrm{mM}$ ) and hydrogen peroxide $\left(\mathrm{H}_{2} \mathrm{O}_{2}, 5 \mathrm{mM}\right)$. The swelling ratio was determined by the \% swelling $\left(W_{s}-W_{0} / W_{0}\right) \times 100$ (where $W_{s}$ is the mass of the swollen gel and $W_{0}$ is the mass of dried gel). In PBS (pH 7.4), the swelling of the gel derived from P1, with the smallest AsAm mole fraction was $175 \%$ after 24 hours compared to $5 \%$ for P4 with the highest AsAm mole fraction (Fig. 5). Swelling of P1 and P4 was measured every 24 hours 6 days reaching 2040\% and 160\% respectively. After each measurement fresh swelling solution was added to each of the swollen gels.

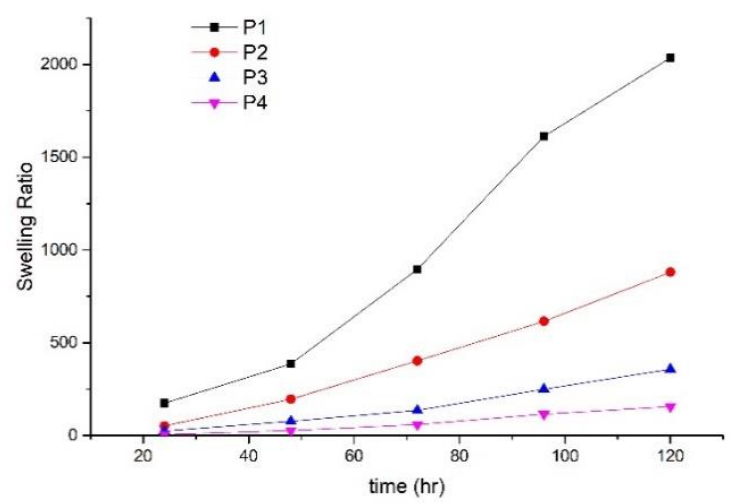

Fig 5. Swelling ratio of the arsenohydrogels derived from P1-P4 calculated as $\left(W_{\mathrm{s}}-W_{0}\right) / W_{0} \times 100$ where $W_{0}$ is the weight of the hydrogel after drying in the oven and $W_{s}$ is the weight of the swollen hydrogel at a definite time interval (Table S3). Swelling was performed in PBS ( $\mathrm{pH} 7.4)$.

The gels derived from $\mathbf{P 2}$ and $\mathbf{P} \mathbf{3}$ followed the same trend, with $\mathbf{P 2}$ reaching $880 \%$ and $\mathbf{P} \mathbf{3}$ reaching $360 \%$ after 6 days of swelling. The 
swelling properties of the arsenohydrogels in PBS (pH 7.4) can be rationalised by the degree of crosslinking and the relative susceptibility of the As-As bonds, that constitute the crosslinking, to hydrolysis and oxidation. Under the reductive conditions imposed during gelation, the formation of As-As bonds is favoured. However, during the swelling experiment, the reducing agent(s) are gradually removed which exposes the relatively weak As-As bonds to hydrolysis and re-oxidation, under ambient conditions, of As(I) to $\mathrm{As}(\mathrm{III})$ and $\mathrm{As}(\mathrm{V})$. The impact of this on the gel integrity is most prevalent at lower crosslinking densities (P1) which exhibit faster rates of swelling and a higher swelling ratio. At the highest crosslinking density (P4) the impact on the gel integrity was minimal. It should be noted that the arsenohydrogels do not reach an equilibrium swelling point, as As-As bond hydrolysis will continue until the gel completely degrades. In this respect the relative swelling ratio and rate can be used as a measure of the relative stability of the gels (i.e. $\mathbf{P} \mathbf{1}<\mathbf{P} \mathbf{2}<\mathbf{P 3}<\mathbf{P 4}$ ). The impact of hydrolysis on the gel integrity also supports the data obtained from SEM (Fig. 4), whereby partial hydrolysis of the As-As bonds in gels derived from P1 and P2 results in loss of the gel microstructure. The swelling rate and ratio of P1 - P4 (and therefore degradation) is attenuated in aqueous GSH (5 mM, Fig. S15, Table S4) which is attributed to a change in the overall redox environment imposed by the reductive nature of GSH which slows down oxidation of As(I). Conversely, under oxidative conditions $\left(5 \mathrm{mM} \mathrm{H}_{2} \mathrm{O}_{2}\right)$ the swelling rate and ratio is significantly accelerated (Fig. S16, Table S5), with P4 reaching 170\% swelling after 24 hours, compared to $5 \%$ in PBS (pH 7.4). This is also attributed to changes in the redox environment, which in the presence of $\mathrm{H}_{2} \mathrm{O}_{2}$. promotes oxidation of $\mathrm{As}(\mathrm{I})$ to $\mathrm{As}(\mathrm{III})$ and/or $\mathrm{As}(\mathrm{V})$.

\section{Gel biocompatibility, loading and release}

For polymeric arsenicals and arsenohydrogels to be considered for biological applications it is important to consider their cytotoxicity. Thus, polymer scaffolds P1-P4 were investigated for toxicity in vitro using a standard XTT assay. NIH/3T3 (mouse embryonic fibroblasts) cells were selected as a model for healthy cells, whilst PC3 (human prostate cancer) cells were also screened for consistency with our previous work and with the long-term aim of developing systems with selective toxicity to malignant cells. In line with our previous results ${ }^{23-25}$ the scaffolds P1-P4 were not toxic towards either NIH/3T3 (Fig. 6A) or PC3 (Fig. 6B) up to relatively high concentrations (0.25 $8 \mathrm{mg} \cdot \mathrm{ml}^{-1}$ ). The potential for cell encapsulation was then examined using freshly prepared arsenohydrogels, thoroughly purified by dialysis to remove excess $\mathrm{H}_{3} \mathrm{PO}_{2}$ and $\mathrm{KI}$. The lyophilised arsenohydrogels were then swollen in the cell growth media containing freshly trypsinized cells $(\mathrm{NIH} / 3 \mathrm{~T} 3$ or PC3), and imaged using nuclei active staining (Hoechst). Freshly trypsinised cells adopt a more spherical morphology compared to those attached to a surface (Fig. 6C). This spherical morphology was apparent for both $\mathrm{NIH} / 3 \mathrm{~T} 3$ and PC3 cells encapsulated within the arsenohydrogel matrices, suggesting that cells remain detached from the surface of the gel or culture plate and retain viability. This was confirmed by zstack tomography (Fig. 6D) which shows that the cells interact with the gel matrix across the entire cell surface. 
A

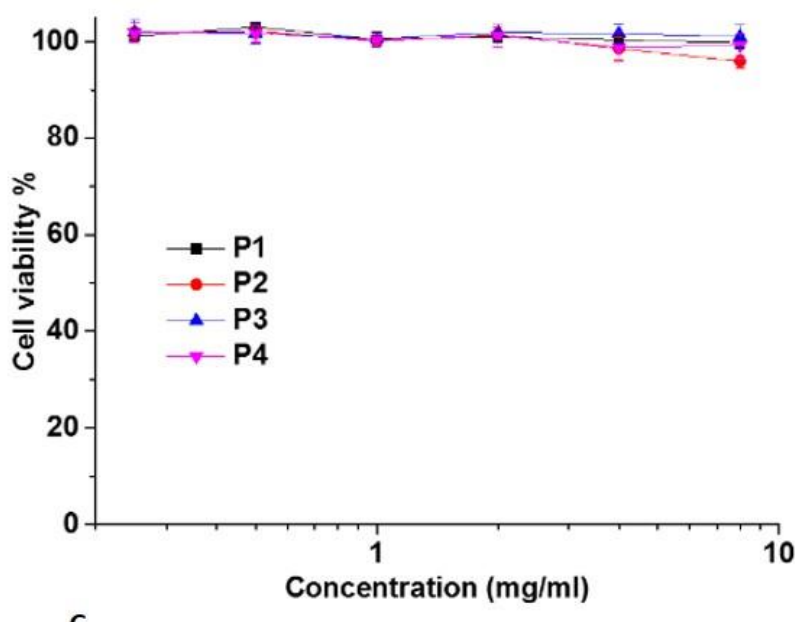

C

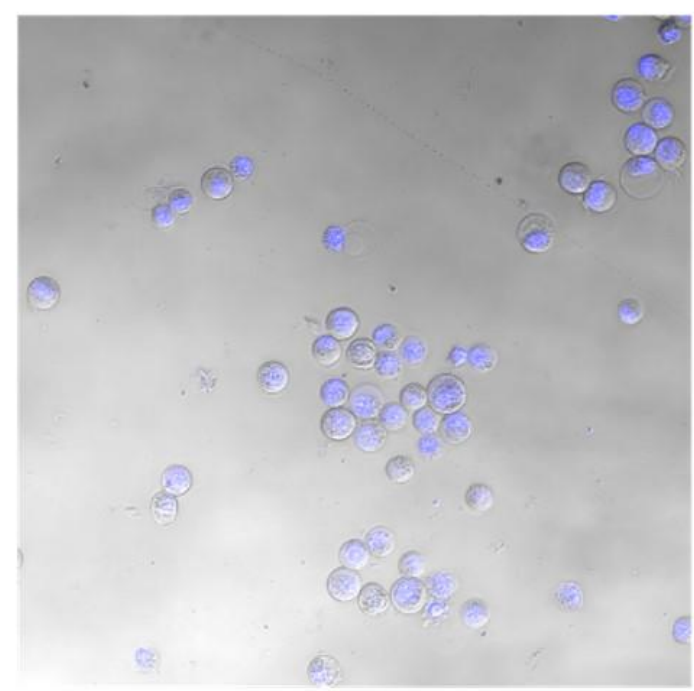

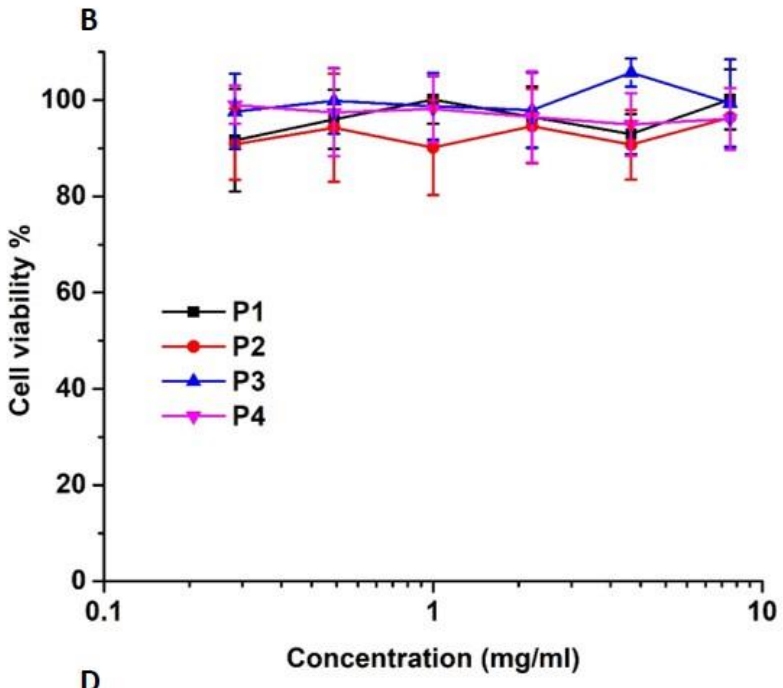

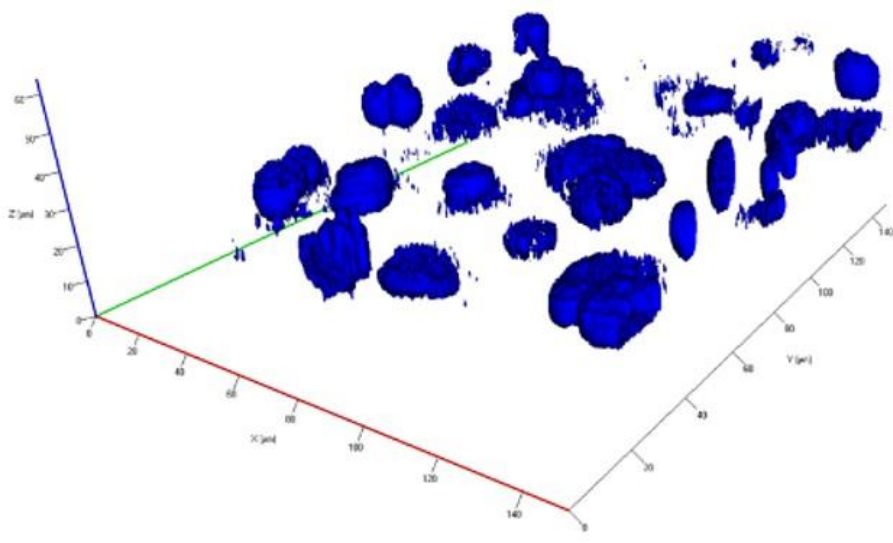

Fig 6. (A) XTT cytotoxicity assay of arsenic functional polymers (P1-P4) with PC3 cells; (B) XTT cytotoxicity assay of arsenic functional polymers (P1-P4) with NIH/3T3 cells; (C) Confocal microscopy of arsenohydrogels (P1, 10 wt\%, after dialysis and lyophilisation) rehydrated with cell media containing PC3 cells: 20 x magnification with bright field and Hoechst stain; (D) z-stack tomography of the PC3 cells encapsulated an arsenohydrogel matrix, imaged with Hoechst dye.

The NIH/3T3 cells were found to be randomly distributed through the gel matrices irrespective of the parent polymer scaffold (P1-P4, Fig S17A-S17D). However, the PC3 cells showed a greater tendency to reside near the surface of the arsenohydrogels with the depth of penetration tentatively related the mole fraction of arsenic within the parent polymer scaffold. For example, the majority of the cells seeded into the gel from P1 were found at a depth of 20-30 $\mu \mathrm{M}$ (Fig 18A), whereas cells seeded with $\mathbf{P 4}$ were found to reside closer to the gel surface ( $<20 \mu \mathrm{M}$, Fig S18D).

The principle of controlled drug release by environmental stimuli has become a central focus in the development of responsive materials for biomedical applications. ${ }^{34}$ Considering the oxidative responsive nature of the arsine bonds, and the clinical relevance of organic arsenicals such as $4-(\mathrm{N}$-(S-penicillaminylacetyl)amino) phenylarsonous acid (PENAO) $^{35}$ and 4-(N-(Sglutathionylacetyl)amino) phenylarsonous acid (GSAO), ${ }^{36}$ the potential to incorporate an organic arsenical as a model therapeutic into the arsenohydrogels was investigated. Thus, it was hypothesised that this could be achieved by physical encapsulation into the gel matrix and/or via covalent incorporation into domains of $\mathrm{As}(\mathrm{I})_{n}$ cyclooligoarsine crosslinking. To investigate this, arsenohydrogels (2.5 wt\%) were prepared in the presence of $p$-arsanilic acid as the model organic arsenical. In the presence of an excess of $p$-arsanilic acid (3.8 wt \%), the initial gelation took longer due to incorporation of the monomeric organic arsenical competing with cross-linking between polymeric arsenical chains. Interestingly, this competition between cross-linking and incorporation of organic arsenical completely eliminated the syneresis observed previously for the gels derived from $\mathbf{P} \mathbf{3}$ and $\mathbf{P} \mathbf{4}$ at $\mathbf{2 . 5 w t} \%$ suggesting a lower overall degree of cross-linking present in each formulation (Fig. S19). The darker 
appearance of the gels compared to those prepared in the absence of $p$-arsanilic acid is attributed to an increase in the formation of the As-As arising from the larger total concentration on $\mathrm{As}(\mathrm{V})$ in each formulation. The relative release of the $p$-arsanilic acid from the arsenohydrogels at room temperature in aqueous solution and under simulated oxidative stress (aqueous $\mathrm{H}_{2} \mathrm{O}_{2}$ ) was monitored by HPLC (Fig. 7). In pure aqueous solution, very little release was observed. Conversely, in an aqueous solution containing a stoichiometric amount (with respect to total arsenic content) of $\mathrm{H}_{2} \mathrm{O}_{2}$ evidence of release of $p$-arsanilic acid was detected over 48 hours until a plateau was reached. A trend in release with respect to copolymer composition was apparent, with the rate and degree of release being inversely proportional $(\mathbf{P 1}>\mathbf{P 2}>\mathbf{P 3}>\mathbf{P 4})$ to the AsAm mole fraction in the copolymer composition $(\mathbf{P} \mathbf{1}<\mathbf{P} \mathbf{2}<\mathbf{P} \mathbf{3}<\mathbf{P 4})$. This was attributed to increased covalent incorporation of the $p$-arsanilic acid into the domains of $\mathrm{As}(\mathrm{I})_{n}$ cyclooligoarsine crosslinking.

\section{Conclusions}

Arsenohydrogels have been successfully prepared for the first time. Reductive coupling of $\mathrm{As}(\mathrm{V})$ to $\mathrm{As}(\mathrm{I})$ has been exploited to crosslink high molecular weight $\left(M_{\mathrm{w}}>300 \mathrm{kDa}\right)$ polymeric arsenical scaffolds (PDMAm $\mathrm{m}_{\mathrm{x}}$-CO-AsAm $\mathrm{m}_{\mathrm{y}}$ ). Arsenohydrogels were formed in the presence of $\mathrm{H}_{3} \mathrm{PO}_{2}$ and $\mathrm{KI}$ when the polymer weight fraction was $\geq 2.5$ wt\% with soft gels that failed under compressive loads at low stress/strain being formed at $2.5 \mathrm{wt} \%$. The mechanical properties of the arsenohydrogels improved when the polymer weight fraction was increased to $10 \mathrm{wt} \%$. Increasing the AsAm mole fraction (P1 - P4) resulted in arsenohydrogels with increased stiffness $(Y=193-228 \mathrm{kPa})$ Moreoever, increasing the AsAm mole fraction reduced swelling capacity of the arsenohydrogels and increased their resistance to hydrolysis and oxidation of the As-As crosslinks. The polymeric arsenical scaffolds and the resulting arsenohydrogels were found to be non-toxic in vitro and the gels were capable of encapsulating NIH/3T3 and PC3 cells within a 3D arsenohydrogel matrix. Finally, the arsenohydrogels have been shown to be functional through the loading of $p$-arsanilic acid as model arsenical drug. The relative release of model arsenical drug in aqueous solution and under simulated oxidative stress demonstrates the redox responsive characteristics of systems containing organic arsenicals. This investigation further demonstrates the distinctive reactivity and versatility of organic and polymeric arsenicals, and the properties of this first generation of arsenohydrogels are promising for biomaterials applications in the future.
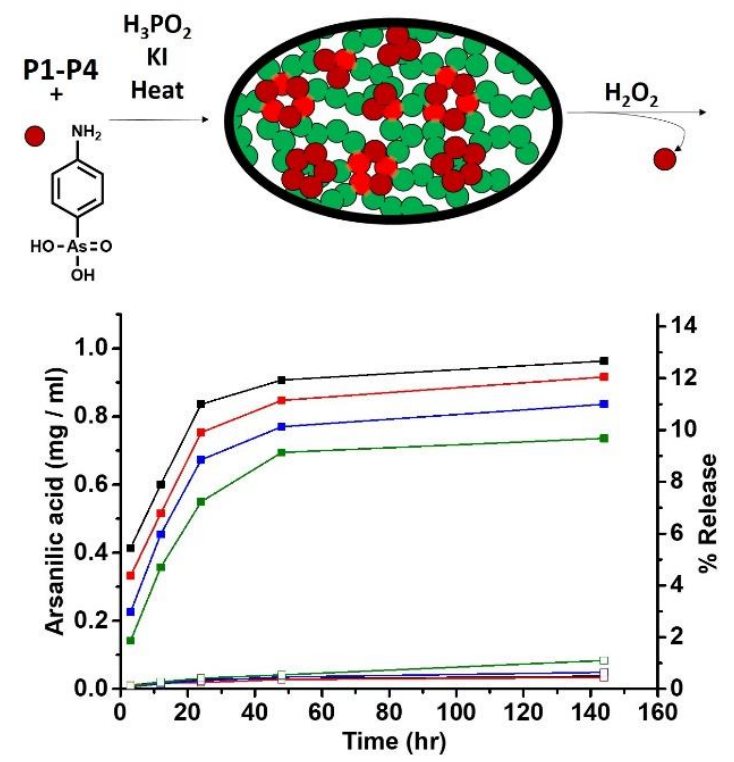

Fig. 7. Release of $p$-arsanilic acid from arsenohydrogels from $\mathbf{P} 1$ (black), P2 (red), P3 (blue) and P4 (green) in aqueous solution (empty) and under simulated oxidative stress using stoichiometric $\mathrm{H}_{2} \mathrm{O}_{2}$ (filled).

\section{Conflicts of interest}

There are no conflicts to declare

\section{Acknowledgements}

The authors gratefully acknowledge financial support from Engineering and Physical Sciences Research Council (EPSRC) under grant EP/F500378/1 through the Molecular Organisation and Assembly in Cells Doctoral Training Centre(MOAC-DTC). The authors also wish to acknowledge the facilities and personnel (S.P., T.P.D., P.W.) enabled by the Monash-Warwick Alliance. This work was carried out in conjunction with the Australian Research Council (ARC) Centre of Excellence in Convergent Bio-NanoScience and Technology (CE140100036). T.P.D. gratefully acknowledges support from the ARC in the form of an Australian Laureate Fellowship. S.P. acknowledges a Royal Society Wolfson Merit Award (WM130055). P.W. is a Royal Society Tata University Research Fellow (URF\R1\180274) and acknowledges the Leverhulme Trust (ECF/2015-075) for prior funding for this work. S.H. acknowledges financial support from Lubrizol. The authors would like to thank Dr Daniel Lester and Dr Steve York, managers of the Polymer Characterisation and electron microscopy Research Technology Platforms for access and maintenance of their facilities.

\section{Notes and references}


1. Z. Yinyu, L. Yongmao and L. Wenguang, Adv. Funct. Mater., 2015, 25, 471-480.

2. A. Erbas and M. O. de la Cruz, ACS Macro Lett., 2015, 4, 857-861.

3. E. A. Appel, J. del Barrio, X. J. Loh and O. A. Scherman, Chem. Soc. Rev., 2012, 41, 6195-6214.

4. A. Gutierres, S. Pascual, L. Fontaine, S. Pioge and L. Benyahia, Polym. Chem., 2018, 9, 2494-2504.

5. M. J. Webber, E. A. Appel, E. W. Meijer and R. Langer, Nat. Mater., 2016, 15, 13-26.

6. Y. S. Zhang and A. Khademhosseini, Science, 2017, 356.

7. C. Zhu, J. Zhao, K. Kempe, P. Wilson, J. Wang, T. Velkov, J. Li, T. P. Davis, M. R. Whittaker and D. M. Haddleton, Macromol. Biosci., 2017, 17, 1600320.

8. I. Y. Jung, J. S. Kim, B. R. Choi, K. Lee and H. Lee, Adv. Healthcare Mater., 2017, 6.

$9 . \quad$ B. Yang, Y. Zhang, X. Zhang, L. Tao, S. Li and Y. Wei, Polym. Chem., 2012, 3, 3235-3238.

10. J. Carthew, J. E. Frith, J. S. Forsythe and V. X. Truong, J. Mater. Chem. B, 2018, 6, 1394-1401.

11. M. Liu, X. Zeng, C. Ma, H. Yi, Z. Ali, X. B. Mou, S. Li, Y. Deng and N. Y. He, Bone Res., 2017, 5.

12. H. Kai, T. Yamauchi, Y. Ogawa, A. Tsubota, T. Magome, T. Miyake, K. Yamasaki and M. Nishizawa, Adv. Healthcare Mater., 2017, 6, DOI: 10.1002/adhm.201700465.

13. J. J. Cash, T. Kubo, D. J. Dobbins and B. S. Sumerlin, Polym. Chem., 2018, 9, 2011-2020.

14. H. Towbin, T. Staehelin and J. Gordon, Proc. Natl. Acad. Sci. U. S. A. $1979,76,4350-4354$.

15. D. Roy, J. N. Cambre and B. S. Sumerlin, Prog. Polym. Sci., 2010, 35, 278-301.

16. Y. Yang and M. W. Urban, Chem. Soc. Rev., 2013, 42, 74467467.

17. H. Qian and I. Aprahamian, Chem. Commun., 2015, 51, 11158-11161.

18. F. Karimi, J. Collins, D. E. Heath and L. A. Connal, Bioconjugate Chem., 2017, 28, 2235-2240.

19. J. J. Cash, T. Kubo, A. P. Bapat and B. S. Sumerlin, Macromolecules, 2015, 48, 2098-2106.

20. H. S. Yu, Y. A. Wang, H. Y. Yang, K. Peng and X. Y. Zhang, J. Mater. Chem. B, 2017, 5, 4121-4127.

21. P. J. Dilda and P. J. Hogg, Cancer Treat. Rev., 2007, 33, 542564.

22. J. Tanaka, T. P. Davis and P. Wilson, Macromol. Rapid Commun., 2018, DOI: doi:10.1002/marc.201800205 .

23. C. Footman, P. A. J. M. de Jongh, J. Tanaka, R. Peltier, K. Kempe, T. P. Davis and P. Wilson, Chem. Commun., 2017, 53, 8447-8450.

24. P. Wilson, A. Anastasaki, M. R. Owen, K. Kempe, D. M. Haddleton, S. K. Mann, A. P. R. Johnston, J. F. Quinn, M. R. Whittaker, P. J. Hogg and T. P. Davis, J. Am. Chem. Soc., 2015, 137, 4215-4222.

25. J. Tanaka, S. Tani, R. Peltier, E. H. Pilkington, A. Kerr, T. P. Davis and P. Wilson, Polym. Chem., 2018, 9, 1551-1556.

26. J. Tanaka, G. Moriceau, A. Cook, A. Kerr, J. Zhang, R. Peltier S. Perrier, T. P. Davis and P. Wilson, Macromolecules, 2019, DOI: 10.1021/acs.macromol.8b02459.

27. K. Naka, T. Umeyama and Y. Chujo, J. Am. Chem. Soc., 2002, 124, 6600-6603.

28. N. C. Lloyd, H. W. Morgan, B. K. Nicholson and R. S. Ronimus, Angew. Chem. Int. Ed., 2005, 44, 941-944.
29.

A. Morales-Burgos, E. Carvajal-Millan, Y. López-Franco, A. Rascón-Chu, J. Lizardi-Mendoza, N. Sotelo-Cruz, F. BrownBojórquez, A. Burgara-Estrella and M. Pedroza-Montero, Polymers, 2017, 9, 164.

30. U. Tomokazu, N. Kensuke and C. Yoshiki, J. Polym. Sci. Part A: Polym. Chem., 2004, 42, 3023-3028.

31. U. Tomokazu, N. Kensuke and C. Yoshiki, J. Polym. Sci. Part A: Polym. Chem., 2004, 42, 3604-3611.

T. Umeyama, K. Naka and Y. Chujo, Macromolecules, 2004, 37, 5952-5958.

33. T. Umeyama, K. Naka, A. Nakahashi and Y. Chujo, Macromolecules, 2004, 37, 1271-1275.

34. J. Y. Li and D. J. Mooney, Nat. Rev. Mater., 2016, 1.

35. P. J. Dilda, S. Decollogne, L. Weerakoon, M. D. Norris, M. Haber, J. D. Allen and P. J. Hogg, J. Med. Chem., 2009, 52, 6209-6216.

36. L. Horsley, J. Cummings, M. Middleton, T. Ward, A. Backen, A. Clamp, M. Dawson, H. Farmer, N. Fisher, G. Halbert, S. Halford, A. Harris, J. Hasan, P. Hogg, G. Kumaran, R. Little, G. J. M. Parker, P. Potter, M. Saunders, C. Roberts, D. Shaw, N. Smith, J. Smythe, A. Taylor, H. Turner, Y. Watson, C. Dive and G. C. Jayson, Cancer Chemother. Pharmacol., 2013, 72, 1343-1352. 